\title{
Studying Law in Society: Static and Dynamic Conceptions of Social Norms
}

\author{
Jing Hiah \& Thomas Riesthuis*
}

\section{Introduction}

This issue of Erasmus Lam Reviem explores the relation between law and society by investigating different conceptions of social norms. The idea of this special issue saw the light of day during the meetings of a discussion group that we organised for our fellow $\mathrm{PhD}$ candidates of the Erasmus Graduate School of Law (EGSL). The aim of the discussion group was to stimulate debate among peers and thereby benefit from the diverse disciplinary backgrounds of the participating $\mathrm{PhD}$ candidates and guest speakers. In exploring the relation between law and society we have found it both helpful and challenging to focus, in particular, on the relation between legal and social norms. Although norms are central concepts in both law and the social sciences, ${ }^{1}$ we have observed great variety in the way norms are conceptualised. Both the exchanges in the discussion group and the contributions to this issue illustrate that legal norms and social norms can be understood in different ways. From a legal perspective, norms include legal rules and principles laid down in, for example, an Act of Parliament, and can be seen as closely linked to state authority. ${ }^{2}$ However, not all scholars agree that state authority is necessary to consider a norm to be a legal norm. ${ }^{3}$ The definition of social norms is ambiguous. ${ }^{4}$ There is no consensus among social science scholars on the question of how social norms should be conceptualised. ${ }^{5}$ A social science (sub)discipline that studies social norms as its main occupancy is non-existent. Actually,

* $\quad$ Jing Hiah is PhD candidate at the Department of Criminology, Erasmus University Rotterdam (hiah@law.eur.nl). Thomas Riesthuis is PhD candidate at the Department of Sociology, Theory and Methodology, Erasmus University Rotterdam (riesthuis@law.eur.nl).

1. See e.g. the discussion in M. Svensson, 'Norms in Law and Society: Towards a Definition of the Socio-legal Concept of Norms', in M. Baier (ed.), Social and Legal Norms: Towards a Socio-legal Understanding of Normativity (2013) 39. We have excluded moral norms in this issue as our primary concern is the relation between legal and social norms. On moral norms in relation to social and legal norms, see e.g. G. Brennan, L. Eriksson, R.E. Goodin \& N. Southwood, Explaining Norms (2013), at 5-7.

2. Brennan et al, above n. 1, at 5 .

3. See e.g. the discussion in B. Tamanaha, A General Jurisprudence of Law and Society (2001), at 173ff.

4. C. Horne. 'Sociological Perspectives on the Emergence of Social Norms', in M. Hechter and K.D. Opp (eds.), Social Norms (2005) 3, at 3-4.

5. Ibid social science (sub)disciplines apply a variety of terms to refer to similar or overlapping notions of norms. Relevant terms include custom, convention, role, identity, institution and culture. ${ }^{6}$

In our view, social norms can be defined as social phenomena that prescribe and/or proscribe behaviour in certain circumstances and that are considered to be at least partly responsible for regulating social behaviour. ${ }^{7}$ However, not every (sub)discipline in the social sciences or law that investigates the relation between law and society actively reflects on how social norms might be conceptualised. Hence, the process of editing this issue was challenging in some respects because our aim was to develop a topic that would be broad enough to be of interest to a wide audience, yet also contribute to existing academic discussions in studies on law and society. As the contributions of this issue illustrate, a wide variety of conceptualisations of social norms are applied to study the relationship between law and society. In our attempt to grasp the various conceptions of social norms, we have found it helpful to establish a continuum of conceptions of social norms. Following Banakar and Travers' distinction between consensus and conflict approaches in the field of sociology, ${ }^{8}$ we have found it helpful to distinguish between static and dynamic conceptions of social norms. ${ }^{9}$ This continuum between static and dynamic conceptions of social norms is informed by classic epistemological debates in social theory on consensus versus conflict, structure versus agency perspectives, and postmodernism. ${ }^{10}$ Static conceptions stress that social norms arise out of a situation of consensus in society. Generally held social norms are constitutive of a society in this conception. A dynamic conception of social norms denies that a general consensus could exist in a given society that would inform generally held social norms. Instead, social norms represent at the most a limited consensus. Generally held beliefs can differ between social groups and change over time. ${ }^{11}$

6. Ibid

7. M. Hechter and K.D. Opp, 'Introduction', in M. Hechter and K.D. Opp (eds.), Social Norms (2005) xi.

8. R. Banakar and M. Travers, 'Introduction', in R. Banakar and M. Travers (eds.), Law and Social Theory (2013) 1, at 4-6.

9. On consensus and conflict approaches, see also e.g. I. Marsh, M. Keating, S. Punch \& J. Harden, 'Sociological Theories', in I. Marsh, M. Keating, S. Punch \& J. Harden (eds.), Sociology: Making Sense of Society (2009) 45

10. On these debates, see Banakar and Travers, above n. 8, at 4-8.

11. Scholars who rely on a dynamic conception of social norms sometimes avoid referring to norms because the term might suggest that a general consensus could exist or develop in society. 
Scholars who explore the relation between law and society often rely on a specific conception of social norms. In the following sections we intend to illustrate how a static conception (Section 2) and a dynamic conception of social norms (Section 3) may impact how one understands the complex relation between law and society. Based on the contributions of this issue, we illustrate how a particular conception of social norms may materialise with both its strengths and weaknesses. In the following sections we will elaborate on our 'continuum' of social norms by sketching the theoretical landscape of this continuum and reflecting on where and how the three contributions of this issue fit. Because we consider that no rigid or clear-cut distinction can be made between static and dynamic conceptions of social norms, we will begin with the contributions at one end of the continuum. Our landscape starts with static conceptions of social norms, that is the economic insights provided by rational choice theories, and then goes on to consider generally shared beliefs or values, as theorised by Durkheim. We will then move towards more dynamic conceptions of social norms to which critical and interpretivist approaches belong.

\section{Static Conceptions of Social Norms: Consensus in Rationality and Values}

Static conceptions of social norms can often be found in theories that approach law and society from a rational choice perspective. Yuan's contribution to this issue, for example, explains how in transnational mercantile practice both social and legal norms have developed over time. These norms aim to regulate the behaviour of parties in conducting their business. In this contribution, rational choice theories are used to explain the development of these norms in the field of transnational business law. Generally, rational choice theories explain how the behaviour of individuals is informed by a cost and benefit analysis. ${ }^{12}$ These theories approach society from an economic perspective in which individuals are deemed to behave rationally, meaning that individuals aim to further their preferences. ${ }^{13}$ Theories that analyse how individuals determine what behaviour would benefit their preferences explain social norms in terms of costs and benefits. From the perspective of rational choice theories, certain patterns of behaviour would be rational given particular circumstances and thus

12. See e.g. the collection of essays in J. Elster (ed.), Rational Choice (1986).

13. For a discussion of these theories in the field of sociology, see e.g. C. Silling and P.A. Mellor, The Sociological Ambition: Elementary Forms of Social and Moral Life (2001), at 164-184, and in the field of criminology R.H. Burke, An Introduction to Criminological Theory (2014), at 29-77. improve overall utility. ${ }^{14}$ Social norms can therefore be explained in terms of a consensus between rational individuals. ${ }^{15}$ As rational choice theories emphasise that social norms exist because they provide overall benefits to individuals, ${ }^{16}$ social norms also need to be understood in light of these costs and benefits. A number of characteristics follow from a rational choice perspective on law and society. First, by approaching social norms from a rational choice perspective, enforcement becomes an important issue of concern. Social norms need to be enforced as free riders may try to gain benefits without incurring costs when following a social norm. ${ }^{17}$ Enforcement therefore ensures that social norms are followed by individuals. Second, rational choice theories explain social norms, first and foremost, at the level of individual behaviour. A different static conception of social norms may be more fruitful if one wishes to approach the relation between law and society from a macro perspective.

A macro perspective on the relation between law and society that relies on a static conception of social norms is possible if one approaches social norms in terms of generally shared beliefs or values. Pei's contribution to this issue, for example, explains how a particular form of alternative dispute resolution in the Chinese legal system, criminal reconciliation, is informed by the generally held belief in Chinese society that disputes between individuals should be resolved in an informal manner. She describes, from a historical perspective, how this generally shared value has been reflected in the Chinese criminal justice system. The idea of values as signalling a general consensus within society can be found in the work of sociologist Émile Durkheim. In his The Division of Labor in Society, Durkheim makes a distinction between mechanical solidarity and organic solidarity. ${ }^{18}$ Mechanical solidarity exists in societies where individuals share the same values. Organic solidarity, on the other hand, exists in societies where individuals, in light of the division of labor, may pursue different values. In his later work, however, Durkheim argues that individualism actually does provide a shared frame of reference, based on which individuals can pursue different values within a society insofar as they respect each other's autonomy. ${ }^{19}$ Durkheim's ideas about solidarity illustrate how a form of shared consensus within society could give rise to social norms. Static conceptions of social norms that focus on shared beliefs or values are able to explore how values in a society are reflected in a legal system. Durkheim, for example, claimed that mechanical solidarity corresponds to a particular form of law, which he called repressive lam. Organic solidarity, on the other hand, is reflected in what Durkheim called restitutive lam.

14. T. Voss, 'Game-theoretical Perspectives on the Emergence of Social Norms', in M. Hechter and K. Opp (eds.), Social Norms (2001) 105.

15. Silling and Mellor, above n. 13, at 176.

16. Voss, above n. 14 , at $110 \mathrm{ff}$.

17. Id. $113 \mathrm{ff}$

18. E. Durkheim, The Division of Labor in Society (1997).

19. See R. Cotterrell, Émile Durkheim: Law in a Moral Domain (1999), at 112-115 
Although Cotterrell has argued that Durkheim did not subscribe to this view in his later work, ${ }^{20}$ Durkheim's ideas about values do provide an intuitive understanding of the relation between law and society. More generally, the view that social values should be reflected in a legal system has been called by Tamanaha the mirror thesis. ${ }^{21}$ By conceptualising the relation between law and society in this way, one can investigate whether generally shared values in a society are adequately reflected in the law. However, Tamanaha is also critical of the mirror thesis. One of his critiques is that society is actually not reflected in the law, as the mirror thesis would suggest. Western legal systems, in his view, do not actually reflect any substantive values held in society. This in turn brings to the fore the importance of procedures that ensure that law is generally recognised as valid. ${ }^{22}$

\section{Dynamic Conceptions of Social Norms: Complexity and Conflict}

Dynamic conceptions of social norms see not consensus, but diversity as the central determinant of social life. As society, according to thinkers of the more dynamic persuasion, is complex, diverse and ever changing, it is impossible to assume that social organisation is based on general consensus. People and groups often have competing and conflicting interests. ${ }^{23}$ Following Tamanaha's mirror thesis, one could, for example, explore how a particular part of society is reflected in a legal system. ${ }^{24}$ Critical approaches to law and society, in particular, are able to explore this issue. Critical approaches in social theory emphasise the role of conflict rather than consensus in society, and this tradition frames social life in terms of a power struggle between the dominant and subordinate groups. The critical tradition has its offspring in the ideas of Karl Marx. Law in this perspective is seen as implicated fully in economic exploitation and the upholding of social relations that generate inequality. ${ }^{25}$ Law is considered representative of the interests of those in power. In this critical perspective, social norms are equally treated sceptically, as what is considered to be a social norm strongly depends on stratification in society. A critical approach to law and society is not illustrated in the contributions to this issue. However, the critical school is the largest and most influential tradition in the studies of law in society, at least in the English-speaking world. ${ }^{26}$

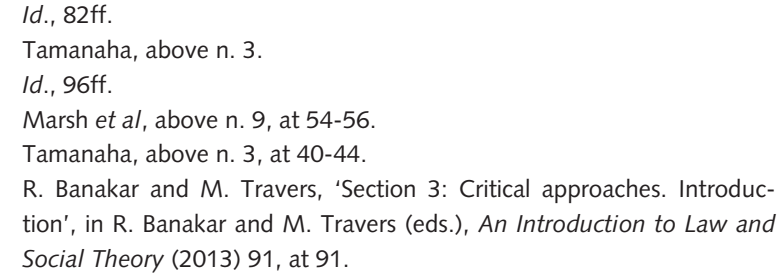

Dynamic conceptions of social norms can also focus on individuals and groups of individuals in a diverse society. The last contribution by Thaddeus Müller provides us with an insightful example of an interpretivist approach to law and society. The interpretivist tradition has a dynamic and diversified conception of social life in which meaning is established on the basis of human interactions. Distinct from the critical tradition, which studies social class groupings, the interpretivist project studies the individual. Interpretivists depart from the idea that people are thinking, reasoning beings who attach meanings to what they do. The general aim of the interpretivist is therefore to address how people understand and justify their own behaviour. Max Weber's concept of verstehen points to the methodological implications of how to carry out this type of research; instead of looking at human beings from the outside, through pre-formed categories, the principle of verstehen points to discovering and understanding the meanings people give to their own behaviour. Interpretivists aim to describe and explain this so-called internal perspective. Weber applied his methodology to explain large-scale social changes in society, and he is perhaps most known for his work on the Protestant ethic and how it contributed to the rise of industrialisation in Western Europe. ${ }^{27}$ Contemporary researchers in the interpretivist paradigm, of which symbolic interactionism is perhaps the most well established, ${ }^{28}$ have applied Weber's methodology to the processes of social interaction in daily life of people in specific small-scale contexts. ${ }^{29}$ Müller, for example, highlights how interpersonal relationships between enforcement officials and youth in public space are crucial to the way social control in public space is enforced in Dutch society. As Müller shows in his contribution, symbolic interactionists emphasise the symbolic meaning of individual behaviour. He argues that owing to a lack of trust between enforcement agents and youth hanging around in public space in urban areas, the behaviour of youth in public space in the big cities is scrutinised more closely. During these interactions between youth and police, symbolic notions of masculinity may further inflate the interaction. Finally, Müller's contribution shows that a symbolic interactionist approach to social norms can be combined with a more critical element when changing the unit of analysis from a micro interactional approach to a macrostructural approach. By comparing the differences between how youth in urban and rural areas are policed, Müller is able to explore why immigrant youth are more often perceived as deviant in Dutch society. When compared with indigenous youth, immigrant youth more often live in urban areas and therefore most likely hang around in public space in urban areas. Because public space in urban areas is scrutinised more closely than public space

\footnotetext{
27. Marsh et al, above n. 9, at 63-70.

28. Id., 72-73.

29. Ibid.
} 
in rural areas, this difference in policing could be seen as a bias against immigrant youth in criminal policy. ${ }^{30}$

\section{Conclusion and Acknowledgements}

Our survey of the contributions to this issue demonstrates that different conceptions of social norms may inform how one views or understands the relation between law and society and hence influences the conclusions you make as a scholar. The conceptual continuum between static and dynamic conceptions of social norms can be utilised to reflect on one's own understanding of social norms. The contributions to this issue can be read as illustrations of particular conceptions of social norms. We would consider Yuan and Pei's contributions to belong to the static side of our continuum. Yuan's contribution uses economic theories to explore how transnational norms develop in business law, while Pei investigates how generally held beliefs on litigation have taken form in the Chinese criminal justice system. Müller's contribution, on the other hand, relies on a dynamic conception of social norms to examine the differences in policing of indigenous and immigrant youth. As editors we would like to express our gratitude to several persons that played a role in the realisation of this issue. We would like to thank EGSL for its financial support for both the discussion group meetings and this special issue. We thank Elaine Mak for motivating us to organise this special issue, René van Swaaningen and Sanne Taekema for providing feedback on our first thematic ideas of the discussion group. Last, but certainly not least, we would like to thank especially Ellen Hey for her sharp critiques and endless patience in mentoring us.

30. Although not explored in the contributions to this issue, as editors we were interested in how postmodern approaches to law and society would fit in the continuum of static and dynamic conceptions of social norms. In postmodern approaches, legal and social norms are considered discursive practices that generate binary and hierarchical relationships. Furthermore, in a world of discourse, norms no longer prescribe behaviour; they are performative. Postmodern approaches could therefore scrutinise our view that law and society can be explored in terms of norms. On postmodern approaches to law and society in general, see e.g. R. Banakar and M. Travers, 'Section 5: Postmodernism. Introduction', in R. Banakar and M. Travers (eds.), Law and Social Theory (2013) 211 , and the contributions to this volume. 